\title{
Factors Associated With Choice of Pharmacy Setting Among DoD Health Care Beneficiaries Aged 65 Years or Older
}

\author{
Andrea Linton, MS; Mathew Garber, PhD; Nancy K. Fagan, DVM, PhD; \\ and Michael Peterson, DVM, DrPH
}

\begin{abstract}
BACKGROUND: Department of Defense (DoD) health care planners want to stimulate a voluntary migration of prescription fills from military and community pharmacies to its mail-order pharmacy, a lower-cost dispensing option for the department. Beneficiary cost share for a 90-day supply of generic/ brand medication is $\$ 0 / \$ 0$ at military $(\mathrm{DoD})$ pharmacies, $\$ 3 / \$ 9$ at the DoD mail-order pharmacy, and $\$ 9 / \$ 27$ at network community pharmacies.

OBJECTIVE: To examine the pharmacy use patterns among the beneficiary population age 65 years or older, traditionally the heaviest users of the TRICARE DOD prescription drug benefit, to identify factors that are associated with beneficiary use of pharmacy setting(s).

METHODS: Outpatient prescription fill records were examined for TRICARE beneficiaries age 65 years or older $(\mathrm{N}=300,084)$ residing in North Carolina, Texas, and California for dates of service from December 1, 2004 through February 28, 2005. Binary logistic regression models were run for each type (military, community, and mail order) and number of pharmacy settings used by beneficiary gender, age group, catchment area status (located either within or outside a 40-mile radius of each military pharmacy), state, and number of medications obtained (defined as count of unique combinations of strength, and route of administration). The mean number of medications per beneficiary and cost per medication were tabulated for each type and number of settings used.
\end{abstract}

RESULTS: In the 3-month period from December 1, 2004 through February 28, 2005 , beneficiary use of military, community, and mail-order pharmacies was $45.4 \%, 67.6 \%$, and $22.1 \%$, respectively. About $67 \%$ of the study population used 1 setting exclusively and $2.4 \%$ used all 3 settings. Noncatchment residents were significantly less likely (adjusted odds ratio $[A 0 R]=0.080$; $95 \%$ confidence interval [Cl], 0.078-0.082) to use a military pharmacy exclusively and significantly more likely to use a community pharmacy (AOR $=4.64 ; 95 \% \mathrm{Cl}, 4.55-4.73)$ or the mail-order pharmacy $(\mathrm{AOR}=3.92 ; 95 \% \mathrm{Cl}$, 3.80-4.05) exclusively than were catchment residents. Beneficiaries taking 10 or more medications were more likely $(\mathrm{AOR}=8.43$; $95 \% \mathrm{Cl}, 8.21-8.65$ ) to use multiple settings than were those who obtained 3 or fewer medications. Single-setting users obtained a median of 4 (interquartile range [IQ]) 2-7) medications with a median copayment of $\$ 7.00$ (IQ $\$ 0-\$ 13.19)$ per medication. Those who used all 3 settings obtained a median of 9 (IQ 7-12) medications with a median copayment of $\$ 4.33$ (IQ $\$ 3.00-\$ 6.00$ ) per medication. Among beneficiaries who obtained 6 or more unique medications during the 90-day study period, approximately $25 \%$ used the mail-order pharmacy to obtain 1 or more prescription fills.

CONCLUSION: A significant portion of the study population did not use the mail-order pharmacy despite the financial incentive to use mail-order rather than community pharmacies. Relatively small financial incentives alone may be inadequate for promoting a switch to the mail-order option among those beneficiaries not already using it in a pharmacy benefit plan with low copayments. Larger monetary and other incentives may be necessary to achieve the desired transfer of prescriptions fills to the mail-order pharmacy and the associated reduction in military pharmacy workload.

KEYWORDS: Department of Defense, Mail-order pharmacy, TRICARE

\begin{abstract}
J Manag Care Pharm. 2007;13(8):677-686
Copyright@ 2007, Academy of Managed Care Pharmacy. All rights reserved.
\end{abstract}

What is already known about this subject

- Many health plans have incorporated mail-order pharmacy as a potentially lower-cost alternative to community pharmacy.

\section{What this study adds}

- Among beneficiaries aged 65 years and older, a small financial incentive ( $\$ 6$ generic/ $\$ 18$ brand out-of-pocket cost savings per 90-day supply) may not be sufficient to achieve a wide spread voluntary shift from community pharmacies to the mail-order pharmacy.

- Geographic proximity to a military pharmacy contributes significantly to the choice of setting.

- The strongest predictor of aged $65+$ beneficiaries' decision making regarding their prescription purchases is the number of unique medications used.

1 The escalating role of prescription pharmaceuticals in disease management, particularly among older adults, has focused greater attention on the nature of the pharmaceutical dispensing environment. Mail-order pharmacies have emerged as an alternative to store-front pharmacies for reducing dispensing-related costs and dispensing errors through centralization and automation, ${ }^{1}$ but the extent to which a mailorder pharmacy option is available to consumers or the factors that influence their use of that option are not clear. Survey-based studies consistently report high consumer satisfaction with insurance plans that include a mail-order pharmacy option, but it is unclear whether ratings are driven by the financial incentives associated with using a mail-order option or a preference for one pharmacy setting over another. ${ }^{2-5}$

Like many health care plans, the Department of Defense (DoD) health care plan, TRICARE, has incorporated a mailorder option to help curb the rising cost of its prescription drug benefit. The TRICARE drug plan offers beneficiaries the option of filling prescriptions at military pharmacies, at community pharmacies, or through the centralized TRICARE mail-order 
pharmacy (TMOP). DoD purchases medications under a federally mandated pricing structure that allows it to stock medications at its military pharmacies and at TMOP at a lower cost than the reimbursements paid to community pharmacies used by TRICARE beneficiaries.

TMOP and the military pharmacies are also able to dispense medications less expensively through centralization and formulary management, and savings are passed on to beneficiaries in the form of reduced cost shares. Thus, DoD has determined that a shift of workload out of the community pharmacies into the military pharmacies and TMOP would be cost-effective for the department and reduce copayments for the beneficiaries. Many military pharmacies, however, already face a heavy workload serving active duty personnel and their families. Rather than further strain the capacity at military pharmacies, DoD wants to motivate a voluntary migration into TMOP, particularly by age $65+$ beneficiaries who are the largest consumers of prescription medications. To accomplish this migration, planners require a better understanding of the factors associated with age 65+ beneficiary use of each pharmacy setting.

We examined a 90-day census of prescription data for a sample of age 65+DoD health care beneficiaries who used their TRICARE benefit to fill their prescriptions. Our objective was to characterize the users of each pharmacy setting and identify key factors associated with use of the mail-order pharmacy option.

\section{The TRICARE Pharmacy Benefit}

The TRICARE pharmacy benefit is available to all DoD beneficiaries, including those 65 years and older. The DoD senior beneficiary population comprises primarily career military service retirees, their spouses, and survivors of deceased service members. Senior veterans and their dependents are eligible for TRICARE when they have completed a full military career before retiring from military service. Beneficiaries require only a valid DoD identification card and a written or electronic prescription from their doctor to use their pharmacy benefit. Beneficiaries may use their TRICARE pharmacy benefit without using any other health care services offered under TRICARE.

The TRICARE pharmacy benefit covers most prescription medications as well as some over-the-counter products (e.g., diabetic supplies). TRICARE does not impose a cap on the drug benefit, but it does place quantity limits and prior authorization requirements on specific medications. TRICARE policy mandates that all prescriptions be filled with a generic product if one is available. However, exceptions may be made to this policy in military pharmacies and in TMOP if DoD can dispense a brand medication at a lower cost than its generic equivalent.

The military pharmacies generally stock medications across all drug classes, but the breadth of inventory may be narrower than for community pharmacies and TMOP, depending on the size of the military pharmacy and the nature of the beneficiary population it supports. For example, the military pharmacy may stock only the generic form or a single brand of a medication in a given drug class, such as generic omeprazole and brand rabeprazole, but not brand omeprazole, lansoprazole, pantoprazole, or esomeprazole in the class of proton-pump inhibitors. TMOP typically offers the same breadth of brand and generic medications that is available from community pharmacies.

During our study period, a beneficiary's cost share depended on the pharmacy setting and whether the drug was generic or brand, as shown in Table 1. Military and mail-order pharmacies could dispense up to a 90-day supply of medication at a time, free of charge or with 1 copayment, respectively. Community pharmacies charged 1 copayment for each 30-day (or less) supply of medication. A 90-day supply was the maximum amount of medication that could be dispensed at a time from any pharmacy setting. Thus, a 90-day supply of medication would be associated with a copayment of $\$ 0$ at a military pharmacy, $\$ 3$ or $\$ 9$ at TMOP, and $\$ 9$ or $\$ 27$ at a network community pharmacy for generic and brand medications, respectively. Use of non-network pharmacies has higher associated cost shares for the beneficiary and is an option used primarily by beneficiaries residing overseas and in remote locations in the United States.

DoD contracts with Express Scripts Inc., a private company, to administer the TRICARE mail-order pharmacy program. Beneficiaries may fill prescriptions by mail, phone, or fax, or online, and any beneficiary may use the mail-order option. Beneficiaries who have prescription drug coverage from other health insurance (OHI), however, can use the TRICARE mailorder pharmacy only if (1) the medication is not covered under their OHI or (2) they have exceeded the dollar limit of coverage under their OHI. Federal law mandates that $\mathrm{OHI}$ is the first payer for mail-order prescription services for TRICARE beneficiaries

\section{TABLE 1) Beneficiary Copayment Amount and Maximum Days Supply per Copayment for Generic and Brand Medications by Pharmacy Setting Used}

\begin{tabular}{l|c|c|c|c}
\hline $\begin{array}{c}\text { Type of } \\
\text { Medication }\end{array}$ & $\begin{array}{c}\text { Military } \\
\text { Pharmacy }\end{array}$ & $\begin{array}{c}\text { Network } \\
\text { Community }\end{array}$ & $\begin{array}{c}\text { Non-network } \\
\text { Community }\end{array}$ & $\begin{array}{c}\text { Mail } \\
\text { Order }\end{array}$ \\
\hline Generic & $\$ 0$ & $\$ 3$ & $\$ 9$ or $20 \% *$ & $\$ 3$ \\
\hline Brand & $\$ 0$ & $\$ 9$ & $\$ 9$ or $20 \% *$ & $\$ 9$ \\
\hline $\begin{array}{l}\text { Maximum } \\
\text { Supply } \\
\text { Per Copay }\end{array}$ & 90 days & 30 days & 30 days & 90 days \\
\hline
\end{tabular}

*The larger of the 2 amounts is paid after a point-of-service deductible is applied; the deductible is usually $\$ 150$ per sponsor (military service beneficiary) or $\$ 300$ per family. 
who carry OHI, because OHI may not be used to purchase medications obtained under the federal pricing structure. ${ }^{6}$ Beneficiaries who wish to use their $\mathrm{OHI}$ and their TRICARE benefit to obtain medications covered under both plans are directed to a network community pharmacy. The use of $\mathrm{OHI}$ by study beneficiaries to purchase prescription medication occurred infrequently.

\section{Methods}

DoD maintains an enterprise-wide information system that captures patient demographic and prescription information for each prescription filled by a beneficiary using his or her TRICARE pharmacy benefit. A fill record is created in real time when the prescription is filled, regardless of whether a military or community pharmacy or TMOP is used. The fill records are forwarded to a central data repository for processing to remove transactions that have been reversed (e.g., prescriptions that were filled but never picked up) and coded with an auto-generated, encrypted patient identifier that enables researchers to link pharmacy and health care service records for the same person without including any protected health information in the study datasets. This data repository was the source for the data used in this study.

We examined prescription fill data for residents in 3 target states-North Carolina, Texas, and California-to account for the possibility of regional differences in pharmacy use. Each state represents 1 of the 3 TRICARE regions nationwide-North (North Carolina), South (Texas), and West (California)in which the uniform health care benefit is independently administered. Each of these states also contains a large age 65+ beneficiary population and multiple military pharmacies where beneficiaries may obtain prescription medication at no out-ofpocket cost. Collectively, these 3 states comprise approximately $25 \%$ of the age $65+$ DoD beneficiary population nationwide.

A census of outpatient pharmacy fill records for beneficiaries aged 65 years and older who resided in the target states for a 90-day period (December 1, 2004 through February 28, 2005) was extracted from this central repository. Fill records associated with the 171 beneficiaries who relocated from or to a target state during the study period were eliminated from the sample. Approximately $0.7 \%$ of the fill records were then excluded from the dataset because they were missing data or they represented medications administered by a clinician during a clinic visit. The resulting 2,726,608 fill records were aggregated into unique beneficiary records that included all prescriptions filled during the study period. The final study dataset included fill records corresponding to 1,857,268 unique medications dispensed to 300,084 beneficiaries.

The number and percentage of beneficiaries residing in each target state were tabulated by beneficiary gender, age group and catchment status, number of prescription medications obtained, types of pharmacy settings used, and number of pharmacy settings used during the 90-day study period. Beneficiaries were categorized as catchment residents if they resided within a 40-mile, ZIP code-based radius of a military hospital (housing a large military pharmacy with a large drug inventory) or within a 20-mile, ZIP code-based radius of a military clinic (housing a smaller military pharmacy with a smaller drug inventory). DoD established these hospital and clinic catchment areas to define its health care service areas and perform demand forecasting and management analyses to ensure sufficient capacity for the beneficiary population. Beneficiaries who did not reside within these areas were designated as noncatchment residents. The number of medications was defined as the total number of unique medications filled during the study period, as identified by the First DataBank generic code number (GCN). Each GCN specifies the active ingredient, strength, dosage form, and route of administration and provides a method of linking brand drugs with generic equivalent products (i.e., simvastatin $20 \mathrm{mg}$ shares a GCN with Zocor $20 \mathrm{mg}$ ). Thus, each drug (e.g., simvastatin) has multiple GCNs_a GCN for each unique combination of drug strength, and route of administration

Binary logistic regression models were run to predict use of each type of pharmacy setting exclusively and the total number of settings used, by beneficiary gender, age group, catchment status, target state, and number of medications obtained. In the equations predicting use of the pharmacy setting, the dependent variable was coded " 1 " if the setting was used exclusively, and " 0 " if it was not. For the equation predicting number of settings, the dependent variable was coded "0" if only 1 pharmacy setting was used, or "1" if multiple pharmacy settings were used to fill prescriptions during the study period. Backwards stepwise regression was applied using the likelihood ratio statistic $(P<0.05)$ to eliminate variables that did not significantly contribute to use of the setting. The c-statistic was used to evaluate model discrimination. Interaction terms using gender, age group, and catchment status were initially included in the models, but later removed since they did not improve model discrimination.

Finally, the median and interquartile range (IQ) for the number of medications obtained, the patient expenditure, and the patient cost per medication was calculated. All data manipulations and analyses were performed using Statistical Package for Social Sciences (SPSS), Base 10.0. This study was reviewed by the TRICARE Management Activity exempt determination officer on November 21, 2005, and found to be exempt from institutional review board review under 32 CFR 219.101(b)(4).

\section{Results}

The number and percentage of TRICARE pharmacy benefit users by gender, age group, catchment status, and use characteristics in each target state are presented in Table 2. Women outnumbered men in each target state, and the mean age of residents ranged from $73.1(S D \pm 6.1)$ years in North Carolina to 
Factors Associated With Choice of Pharmacy Setting Among DoD Health Care Beneficiaries Aged 65 Years or Older

\section{TABLE 2 Number and Percentage of Beneficiaries by Demographic and Pharmacy Use Characteristics} by Target State

\begin{tabular}{|c|c|c|c|c|c|c|c|c|}
\hline \multirow[b]{2}{*}{ Variable } & \multicolumn{2}{|c|}{ North Carolina } & \multicolumn{2}{|c|}{ Texas } & \multicolumn{2}{|c|}{ California } & \multicolumn{2}{|c|}{ Total } \\
\hline & $\mathrm{n}$ & $\%$ & $\mathrm{n}$ & $\%$ & $\mathrm{n}$ & $\%$ & $\mathrm{n}$ & $\%$ \\
\hline Total beneficiaries & 48,607 & 100.0 & 119,952 & 100.0 & 131,525 & 100.0 & 300,084 & 100.0 \\
\hline \multicolumn{9}{|l|}{ Gender } \\
\hline Men & 22,871 & 47.1 & 55,431 & 46.2 & 58,980 & 44.8 & 137,282 & 45.7 \\
\hline Women & 25,736 & 52.9 & 64,521 & 53.8 & 72,545 & 55.2 & 162,802 & 54.3 \\
\hline \multicolumn{9}{|l|}{ Age group (years) } \\
\hline $65-69$ & 16,707 & 34.4 & 36,412 & 30.4 & 31,999 & 24.3 & 85,118 & 28.4 \\
\hline $70-74$ & 14,786 & 30.4 & 34,687 & 28.9 & 32,746 & 24.9 & 82,219 & 27.4 \\
\hline $75-79$ & 9,044 & 18.6 & 22,709 & 18.9 & 27,262 & 20.7 & 59,015 & 19.7 \\
\hline $80-84$ & 5,496 & 11.3 & 17,452 & 14.5 & 25,058 & 19.1 & 48,006 & 16.0 \\
\hline $85+$ & 2,574 & 5.3 & 8,692 & 7.2 & 14,460 & 11.0 & 25,726 & 8.6 \\
\hline $\begin{array}{l}\text { Mean age } \\
\text { in years [SD] }\end{array}$ & & & & & & & & \\
\hline \multicolumn{9}{|l|}{ Catchment status } \\
\hline Catchment residents & 21,039 & 43.3 & 68,303 & 56.9 & 80,761 & 61.4 & 170,103 & 56.7 \\
\hline Noncatchment residents & 27,568 & 56.7 & 51,649 & 43.1 & 50,764 & 38.6 & 129,981 & 43.3 \\
\hline \multicolumn{9}{|l|}{$\begin{array}{l}\text { Number of unique medications } \\
\text { obtained }\end{array}$} \\
\hline $1-3$ & 13,644 & 28.1 & 33,370 & 27.8 & 43,201 & 32.8 & 90,215 & 30.1 \\
\hline $4-5$ & 10,155 & 20.9 & 24,832 & 20.7 & 29,786 & 22.6 & 64,773 & 21.6 \\
\hline $6-9$ & 14,531 & 29.9 & 36,302 & 30.3 & 37,916 & 28.8 & 88,749 & 29.6 \\
\hline $10+$ & 10,277 & 21.1 & 25,448 & 21.2 & 20,622 & 15.7 & 56,347 & 18.8 \\
\hline Mean medications obtained $[\mathrm{SD}]^{*}$ & & & & & & & & \\
\hline \multicolumn{9}{|l|}{ Type of settings used $\dagger$} \\
\hline Military pharmacy & 20,988 & 43.2 & 57,938 & 48.3 & 57,379 & 43.6 & 136,305 & 45.4 \\
\hline Community pharmacy & 35,823 & 73.7 & 79,481 & 66.3 & 87,609 & 66.6 & 202,913 & 67.6 \\
\hline Mail-order pharmacy & 9,996 & 20.6 & 25,951 & 21.6 & 30,521 & 23.2 & 66,468 & 22.1 \\
\hline \multicolumn{9}{|l|}{ Number of settings used } \\
\hline 1 pharmacy setting & 31,623 & 65.1 & 79,540 & 66.3 & 90,442 & 68.8 & 201,605 & 67.2 \\
\hline Military pharmacy only & 9,085 & 18.7 & 31,089 & 25.9 & 31,045 & 23.6 & 71,219 & 23.8 \\
\hline Community pharmacy only & 19,731 & 40.6 & 41,328 & 34.5 & 49,367 & 37.5 & 110,426 & 36.8 \\
\hline Mail-order pharmacy only & 2,807 & 5.8 & 7,123 & 5.9 & 10,030 & 7.6 & 19,960 & 6.7 \\
\hline 2 pharmacy settings & 15,768 & 32.4 & 37,406 & 31.2 & 38,182 & 29.0 & 91,356 & 30.4 \\
\hline 3 pharmacy settings & 1,216 & 2.5 & 3,006 & 2.5 & 2,901 & 2.2 & 7,123 & 2.4 \\
\hline
\end{tabular}


$75.4(\mathrm{SD} \pm 6.9)$ years in California. The percentage of catchment area residents ranged from $43.3 \%$ in North Carolina to $61.4 \%$ in California. The mean number of medications obtained during the study period ranged from 5.8 $(\mathrm{SD} \pm 4.0)$ medications in California to $6.5(\mathrm{SD} \pm 4.3)$ medications in both North Carolina and Texas. In all target states, community pharmacies were most frequently used by beneficiaries and TMOP was used the least. Approximately $67 \%$ of residents in all target states used 1 pharmacy setting exclusively and only $2.4 \%$ used all 3 pharmacy settings during the study period.

The adjusted odds ratios (AORs) and 95\% confidence intervals (CIs) for the binary logistic regression for each type of pharmacy setting used exclusively during the study period are presented in Table 3. Women were significantly more likely than men to use community pharmacies exclusively $(\mathrm{AOR}=1.36$; 95\% CI, 1.34-1.39), and men are more likely to be exclusive users of the other 2 settings. Military pharmacy use decreased and community pharmacy use increased with increasing beneficiary age. Use of TMOP exclusively peaked with the 70 to 74 -year age group $(\mathrm{AOR}=1.14 ; 95 \% \mathrm{CI}, 1.10-1.19)$ but remained relatively constant compared with patterns observed for other pharmacy settings.

Noncatchment area residents were less likely $(\mathrm{AOR}=0.080$; 95\% CI, 0.078-0.082) to use a military pharmacy and were more likely to use a community pharmacy $(\mathrm{AOR}=4.64 ; 95 \% \mathrm{CI}$, 4.55-4.73) or the mail-order pharmacy $(\mathrm{AOR}=3.92 ; 95 \% \mathrm{CI}$, 3.80-4.05) than were catchment area residents. Texas residents were more likely to use military pharmacies exclusively $(\mathrm{AOR}=$ 1.41; 95\% CI, 1.38-1.44). North Carolina residents were more likely to use community pharmacies exclusively $(\mathrm{AOR}=1.08$; 95\% CI, 1.05-1.12). California residents had a higher likelihood of using the mail-order pharmacy than did residents of were the other 2 states. The likelihood of using the community pharmacy setting exclusively increased as the number of medications obtained increased. The values of the c-statistic indicate that the models accurately predicted $72.0 \%, 72.5 \%$, and $79.8 \%$ of the observed use of mail order, community pharmacy, and military pharmacy settings, respectively.

The AORs and 95\% CIs for the binary logistic regression for the number of pharmacy settings used during the study period are presented in Table 4. Single-setting use was more common among women $(\mathrm{AOR}=1.10 ; 95 \% \mathrm{CI}, 1.08-1.12)$ and noncatchment residents ( $\mathrm{AOR}=1.20 ; 95 \% \mathrm{CI}, 1.18-1.22)$ and generally increased with increasing patient age. Variations in the number of settings used by target state were generally small. Single-setting use decreased and multiple-setting use increased substantially as the number of medications obtained increased. Beneficiaries taking 10 or more medications were more likely $(\mathrm{AOR}=8.43 ; 95 \% \mathrm{CI}, 8.21-8.65)$ to use multiple pharmacy settings than were those who obtained 3 or fewer medications during the 90-day study period. The values of the c-statistic indicate that the models accurately predicted $70.9 \%$ of the ob- served setting use.

Table 5 presents the median and IQ ranges for the number of medications obtained, the total patient expenditure, and the cost per medication during the 90-day study period for the types and number of pharmacy settings used. Users of military pharmacies exclusively incurred the lowest median patient expenditures $(\$ 0)$ and cost per medication $(\$ 0)$, and users of community pharmacy exclusively incurred the highest median patient expenditures (\$57.00 [IQ, \$17.00-\$105.00]) and cost per medication (\$12.21 [IQ, \$8.87-\$17.00]). Overall, as the number of pharmacy settings used increased, the median number of medications obtained and median patient expenditure increased but the median cost per medication decreased. Beneficiaries who used only 1 pharmacy setting obtained a median of 4 (IQ, 2-7) medications and paid a median cost of $\$ 7.00$ (IQ, \$0-\$13.19) per medication. Those who used all 3 pharmacy settings obtained a median of 9 (IQ, 7-12) medications and paid a median cost of $\$ 4.33$ (IQ, $\$ 3.00-\$ 6.00$ ) per medication.

A graphical presentation of the relative percentage of mail-order users and nonusers by the number of medications obtained during the study period is presented in the Figure. The percentage of beneficiaries using mail order increased as the number of medications obtained increased, but the percentage of mail-order nonusers exceeded the percentage of mail-order users by a factor of 2 to 3 , regardless of the number of medications obtained.

\section{Discussion}

Our findings indicate that the strongest predictor of age $65+$ beneficiaries' decision making regarding their prescription purchases is the number of medications (as defined by unique GCN) they obtain. Beneficiaries who obtained relatively few medications were more likely to obtain all their medications from a single pharmacy setting, and residential proximity to a military pharmacy contributed significantly to the choice of setting used. Not surprisingly, catchment residents were more likely to use military pharmacies, where all prescription medications were obtained at no cost to the beneficiaries. Those who lived outside the catchment areas were more likely to use community pharmacies or the mail-order pharmacy, despite the copayment requirements associated with the use of both settings. This finding suggests that the out-of-pocket costs incurred by use of these pharmacies were preferable to spending the time, energy, or expense of travel to a source of copaymentfree medications. This finding is consistent with survey-based findings that found convenience to be a primary consideration in consumers' choice of pharmacy. ${ }^{7}$

The relationship between catchment status and beneficiary decision making diminished among heavier consumers of prescription medication, who were more likely to use multiple types of pharmacies to obtain their medication. These findings 
Factors Associated With Choice of Pharmacy Setting Among DoD Health Care Beneficiaries Aged 65 Years or Older

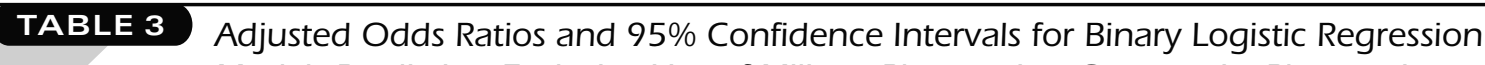
Models Predicting Exclusive Use of Military Pharmacies, Community Pharmacies, and the Mail-Order Pharmacy by Beneficiary Characteristics

\begin{tabular}{|c|c|c|c|c|c|c|}
\hline \multirow[b]{2}{*}{ Variable } & \multicolumn{2}{|c|}{ Military Pharmacy Only } & \multicolumn{2}{|c|}{ Community Pharmacy Only } & \multicolumn{2}{|c|}{ Mail Order Only } \\
\hline & $\mathrm{AOR}$ & $95 \%$ CI & $\mathrm{AOR}$ & $95 \% \mathrm{CI}$ & AOR & $95 \%$ CI \\
\hline \multicolumn{7}{|l|}{ Gender } \\
\hline Men* & * & * & * & * & * & * \\
\hline Women & 0.72 & $0.70-0.73 \dagger$ & 1.36 & $1.34-1.39 \dagger$ & 0.92 & $0.89-0.94 \dagger$ \\
\hline \multicolumn{7}{|l|}{ Age group (years) } \\
\hline $65-69 *$ & & * & & & & * \\
\hline $70-74$ & 0.90 & $0.88-0.93 \dagger$ & 1.03 & $1.01-1.06 \dagger$ & 1.14 & $1.10-1.19 \dagger$ \\
\hline $75-79$ & 0.70 & $0.68-0.73 \dagger$ & 1.28 & $1.24-1.31 \dagger$ & 1.11 & $1.06-1.16 \dagger$ \\
\hline $80-84$ & 0.50 & $0.48-0.52 \dagger$ & 1.72 & $1.66-1.77 \dagger$ & 1.07 & $1.02-1.12 \dagger$ \\
\hline $85+$ & 0.36 & $0.35-0.38 \dagger$ & 2.33 & $2.25-2.42 \dagger$ & 0.92 & $0.86-0.97 \dagger$ \\
\hline \multicolumn{7}{|l|}{ Catchment status } \\
\hline Catchment residents* & & $*$ & & $*$ & & * \\
\hline Noncatchment residents & 0.080 & $0.078-0.082 \dagger$ & 4.64 & $4.55-4.73^{\dagger}$ & 3.92 & $3.80-4.05 \dagger$ \\
\hline \multicolumn{7}{|l|}{ State of residence } \\
\hline California* & & $*$ & & $*$ & & $*$ \\
\hline North Carolina & 1.17 & $1.13-1.21 \dagger$ & 1.08 & $1.05-1.12 \dagger$ & 0.61 & $0.58-0.64 \dagger$ \\
\hline Texas & 1.41 & $1.38-1.44 \dagger$ & 0.84 & $0.82-0.86 \dagger$ & 0.77 & $0.74-0.79 \dagger$ \\
\hline \multicolumn{7}{|l|}{$\begin{array}{l}\text { Number of unique } \\
\text { medications obtained }\end{array}$} \\
\hline $1-3 *$ & & $*$ & & * & & $*$ \\
\hline $4-5$ & 1.11 & $1.08-1.14 \dagger$ & 0.97 & $0.95-1.00$ & 0.89 & $0.85-0.92 \dagger$ \\
\hline $6-9$ & 1.02 & $1.00-1.05$ & 1.24 & $1.21-1.27 \dagger$ & 0.56 & $0.54-0.58 \dagger$ \\
\hline $10+$ & 0.795 & $0.768-0.823 \dagger$ & 1.92 & $1.86-1.98 \dagger$ & 0.19 & $0.18-0.21 \dagger$ \\
\hline C-statistic (95\% CI) & 0.798 & $0.791-0.804$ & 0.725 & $0.718-0.732$ & 0.720 & $0.709-0.731$ \\
\hline
\end{tabular}

*Used as the reference value for the logistic regression.

$\uparrow$ A statistically significant difference relative to the reference value.

The numbers of beneficiaries using military or community pharmacies or the mail-order pharmacy exclusively were 71,219, 110,426, and 19,960, respectively. The number of beneficiaries included in each of the 3 equations was 201,605.

$A O R=$ adjusted odds ratio; $\mathrm{CI}=$ confidence interval.

are consistent with prior studies that found that maintenance medication users are skilled at identifying the most cost-effective source for each medication they use and more motivated to obtain each medication from the source that will minimize their own out-of-pocket expenses. ${ }^{8-10}$ Beneficiary gender and age were lesser but still significant contributors to beneficiaries' use of each type of pharmacy. Women and older adults, who are traditionally the heaviest users of prescription medication, were significantly more likely to use only 1 type of pharmacy setting, likely a community pharmacy, to obtain their medications. Men and younger seniors had a higher likelihood of using multiple settings, military pharmacies, and the mail-order option.
In general, we found that state of residence was a relatively minor contributor to age 65+ pharmacy use patterns compared with other factors examined. We found, however, that California residents obtained the lowest mean number of medications per beneficiary despite having the highest mean beneficiary age. They were also more likely to use TMOP than were residents of North Carolina and Texas, despite having higher proportions of catchment area residents. It is not clear whether these observations are attributable to the differences in regional administration of the TRICARE benefit or a larger phenomenon associated with a regional or California-specific health care culture. Our findings are consistent with a prior Express Scripts study that 
Factors Associated With Choice of Pharmacy Setting Among DoD Health Care Beneficiaries Aged 65 Years or Older

TABLE 4 Adjusted Odds Ratios and 95\% Confidence Intervals for Binary Logistic Regression Models Predicting Use of 1 and Multiple Pharmacy Settings, by Beneficiary Characteristics

\begin{tabular}{|c|c|c|c|c|}
\hline \multirow[b]{2}{*}{ Variable } & \multicolumn{2}{|c|}{ 1-Setting Users } & \multicolumn{2}{|c|}{ Multiple-Setting Users } \\
\hline & $\mathrm{AOR}$ & $95 \%$ CI & $\mathrm{AOR}$ & $95 \%$ CI \\
\hline \multicolumn{5}{|l|}{ Gender } \\
\hline Men* & $*$ & $*$ & $*$ & * \\
\hline Women & 1.10 & $1.08-1.12 \dagger$ & 0.91 & $0.89-0.92 \dagger$ \\
\hline \multicolumn{5}{|l|}{ Age group (years) } \\
\hline $65-69 *$ & $*$ & $*$ & * & $*$ \\
\hline $70-74$ & 0.91 & $0.89-0.93 \dagger$ & 1.10 & $1.07-1.12 \dagger$ \\
\hline $75-79$ & 1.00 & $0.98-1.03$ & 1.00 & $0.98-1.02$ \\
\hline $80-84$ & 1.18 & $1.15-1.21 \dagger$ & 0.85 & $0.83-0.87 \dagger$ \\
\hline $85+$ & 1.59 & $1.54-1.65 \dagger$ & 0.63 & $0.61-0.65 \dagger$ \\
\hline \multicolumn{5}{|l|}{ Catchment status } \\
\hline Catchment residents* & $*$ & $*$ & * & $*$ \\
\hline Noncatchment residents & 1.20 & $1.18-1.22 \dagger$ & 0.83 & $0.82-0.85 \dagger$ \\
\hline \multicolumn{5}{|l|}{ State of residence } \\
\hline California* & * & * & * & * \\
\hline North Carolina & 0.94 & $0.92-0.96 \dagger$ & 1.06 & $1.04-1.08 \dagger$ \\
\hline Texas & 1.02 & $1.00-1.03$ & 0.98 & $0.97-1.00$ \\
\hline \multicolumn{5}{|c|}{ Number of unique medications obtained } \\
\hline $1-3 *$ & * & * & * & * \\
\hline $4-5$ & 0.30 & $0.30-0.31 \dagger$ & 3.30 & $3.21-3.38 \dagger$ \\
\hline $6-9$ & 0.18 & $0.18-0.18 \dagger$ & 5.58 & $5.45-5.72 \dagger$ \\
\hline $10+$ & 0.12 & $0.12-0.12 \dagger$ & 8.43 & $8.21-8.65 \dagger$ \\
\hline
\end{tabular}

*Used as the reference value for the logistic regression.

$\dagger$ A statistically significant difference relative to the reference value. The number of beneficiaries using 1 setting was 201,605, and 98,479 beneficiaries used multiple settings. The number of beneficiaries included in the equation was 300,084.

C-statistic $(95 \% \mathrm{CI})=0.709(0.703-0.715)$.

$A O R=$ adjusted odds ratio; $C I=$ confidence interval.

TABLE 5 Median Number of Medications Obtained, Patient Expenditure, and Cost per Medication by Type and Number of Pharmacy Settings Used

\begin{tabular}{l|c|c|c|c}
\hline Pharmacy Settings & $\mathbf{n}$ & $\begin{array}{c}\text { Median Number of } \\
\text { Medications (IQ) Obtained* }\end{array}$ & $\begin{array}{c}\text { Median Patient Expenditure } \\
\text { (IQ; \$) } \dagger\end{array}$ & $\begin{array}{c}\text { Median Patient Cost } \\
\text { per Medication (IQ; \$) } \neq\end{array}$ \\
\hline All beneficiaries & 300,084 & $5(3-8)$ & $27.00(0.00-63.00)$ & $6.75(0.00-10.82)$ \\
\hline One pharmacy setting used & 201,605 & $4(2-7)$ & $18.00(0.00-66.00)$ & $7.00(0.00-13.19)$ \\
\hline Military pharmacy only & 71,219 & $4(2-7)$ & $0.00(0.00-0.00)$ & $0.00(0.00-0.00)$ \\
\hline Community pharmacy only & 110,426 & $5(2-8)$ & $57.00(17.00-105.00)$ & $12.21(8.87-17.00)$ \\
\hline Mail-order pharmacy only & 19,960 & $3(2-5)$ & $24.00(12.00-39.00)$ & $7.00(6.00-9.00)$ \\
\hline Two pharmacy settings used & 91,356 & $7(5-10)$ & $36.00(18.00-63.00)$ & $5.57(2.77-8.09)$ \\
\hline All pharmacy settings used & 7,123 & $9(7-12)$ & $39.00(24.00-60.00)$ & $4.33(3.00-6.00)$ \\
\hline
\end{tabular}

* Median and IQ range for number of unique medications obtained during the study period.

†Median and IQ range for out-of-pocket expenditures during the study period (cost of refills included).

$¥$ Median and IQ range for cost per medication obtained during the study period (cost of refills included).

$I Q=$ interquartile . 


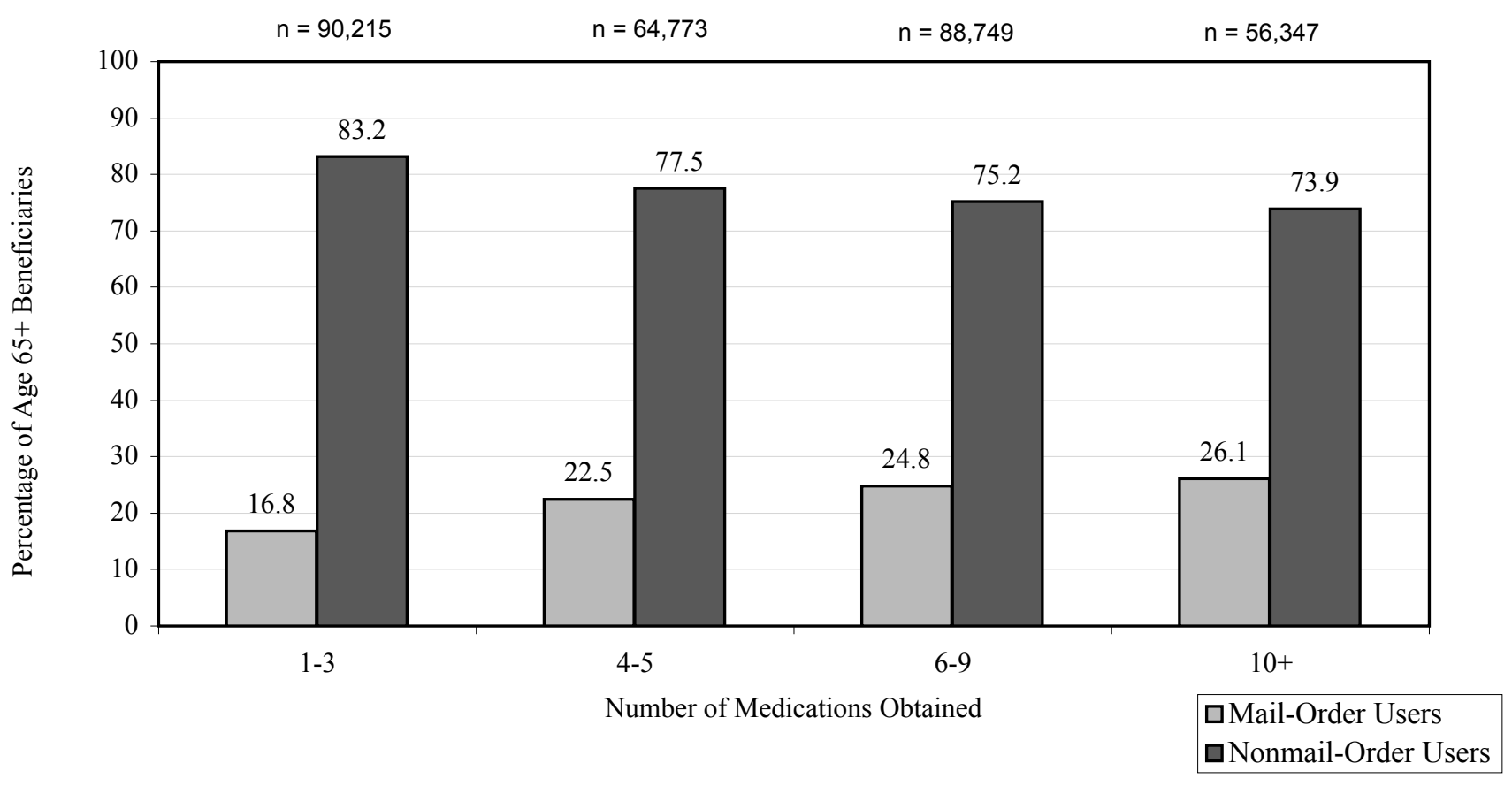

found California had one of the lowest per-member per-year prescription medication use averages in the country. ${ }^{11}$

Increased use of mail-order pharmacies by seniors nationwide has been reported in recent years, presumably as a result of drug plan incentives that increase the days supply of medication obtained per copayment dollar spent. ${ }^{12}$ Clearly, the existing TRICARE copayment structure contains this type of financial incentive to promote use of TRICARE's mail-order pharmacy over community pharmacies. Our findings suggest, however, that the relatively small out-of-pocket generic/brand cost savings of $\$ 6 / \$ 18$ per 90 -day supply of medication has been inadequate for motivating many community pharmacy users to use the mail-order option. Furthermore, use of military pharmacies by $45 \%$ of age $65+$ beneficiaries to obtain copayment-free prescription medications is less expensive for DoD but places a strain on the capacity of military pharmacies, whose first priority is the treatment of active duty personnel so that they may return to duty.

Anecdotal evidence suggests that many beneficiaries, particularly retired active duty personnel, view the trip to the military installation as an opportunity to not only obtain free medications, but also shop at the commissary and coordinate visits with former colleagues and other retired service members. Thus, it is not clear that a reduction or elimination of the copayment requirement under the mail-order program, currently under consideration by DoD planners, would provide an adequate incentive for the $78 \%$ of the beneficiaries who are not mailorder users to begin using TMOP.

The literature includes successful examples of formulary copayment restructuring to motivate the use of generic or preferred medications. ${ }^{13-14}$ Several studies have also observed higher mail-order use among populations covered by plans with larger financial incentives. ${ }^{15-16}$ But few data are available that directly measure changes in mail-order use following implementation of financial incentives that promote voluntary mail-order pharmacy use.

Given the relative convenience and cost savings associated with the existing mail-order program, particularly for noncatchment residents, the low use suggests that beneficiaries may either be unaware of the program or unable or unwilling to use it. Beneficiaries who have traditionally relied on the pharmacist for advice may view the mail-order option with skepticism, particularly older patients who may have a lower comfort level with the concept of a "virtual" drugstore. Any changes to the TRICARE prescription drug benefit should be accompanied by a significant patient education and marketing effort that focuses attention on the benefits and ease of using the mailorder program.

These findings highlight the challenge faced by DoD to stimulate a voluntary migration of the workload associ- 
ated with pharmacy benefits for the aged $65+$ population to TMOP. Among the study population, approximately two thirds of beneficiaries aged 65 or older elected to use a community pharmacy for some or all of their medications, despite it being the most expensive option under the TRICARE pharmacy benefit. Perhaps this choice is because even in community pharmacies, the copayment requirements imposed on TRICARE beneficiaries are substantially lower than those imposed on other insured populations. A national survey of health benefits reported average prescription copayments of $\$ 10, \$ 22$, and $\$ 35$ for generic, preferred, and nonpreferred formulary medications, respectively, for insured workers in 2005. ${ }^{17}$ TRICARE beneficiaries have a relatively rich pharmacy benefit, and the financial incentive to use mail-order pharmacy is small.

It is important to note that some beneficiaries in the present study may have required only 1-time prescription fills for the treatment of an acute condition, and, as such, did not represent good mail-order candidates. Under these circumstances, use of the local community pharmacy would likely have been the most expeditious source for the needed medication. Our findings revealed, however, that approximately $75 \%(n=108,379)$ of study subjects who obtained 6 or more unique medications during the study period did not use the mail-order pharmacy. A prior study on the age 65+ TRICARE beneficiary population found that maintenance medications dominated the medication lists of TRICARE beneficiaries, and treatments for cardiovascular disease, high blood pressure, diabetes, and arthritis topped the list of most commonly used medications. ${ }^{18}$ These beneficiaries represent the ideal target population for DoD's migration initiative for the transfer of prescription fills from community and military pharmacies to TMOP.

\section{Limitations}

The first limitation is the absence of important subjective information regarding beneficiary decision making that drives their pharmacy use patterns. More study is needed to investigate beneficiaries' perceptions of and attitudes toward use of the mail-order pharmacy that ultimately must be addressed to achieve the desired migration of workload out of military pharmacies. Survey-based studies investigating these issues are currently underway.

Second, our reliance on prescription fill data for our study may present other limitations. Our use of GCNs to count medications may have resulted in an overestime of medications used during the study period when beneficiaries filled multiple prescriptions that differed in strength, dosage form, or route of administration. It is also likely that some beneficiaries obtained additional medications not captured in our dataset, including those dispensed outside the 90-day study period or as part of a hospitalization. The study dataset would also not capture fill data for beneficiaries who used other health insurance (without using TRICARE as a second payer) or no insurance to pay for their medication. Third, since our study sample was not drawn randomly from the age $65+$ DoD health care beneficiary population, our findings may not be generalizable to the beneficiaries who resided in nontarget states.

\section{Conclusion}

If DoD intends to succeed in transferring more of the workload associated with providing pharmacy services to TMOP from military and community pharmacies, it will need to address the lack of significant financial or other incentives for beneficiaries to use mail order for maintenance medications

\section{Authors}

ANDREA LINTON, MS, is a senior research associate, Office of the Assistant Secretary of Defense, Health Affairs (OASD[HA]), TRICARE Management Activity (TMA), Health Programs Analysis and Evaluation (HPAEE); MATHEW GARBER, PhD, is deputy director, DoD Pharmacy Programs, OASD(HA)/TMA; NANCY K. FAGAN, DVM, PhD, director of epidemiology, OASD(HA)/TMA (HPAEE); MICHAEL PETERSON, $D V M, D r P H$, is director, HPAEE, OASD (HA).

AUTHOR CORRESPONDENCE: Andrea Linton, Senior Research Associate, Office of the Assistant Secretary of Defense, Health Affairs, TRICARE Management Activity, Health Programs Analysis and Evaluation, 5111 Leesburg Pike, Suite 810, Falls Church, VA 22041. Tel.: (202) 207-5833; Fax: (703) 681-3682

E-mail: andrea.linton.ctr@tma.osd.mil

\section{ACKNOWLEDGMENTS}

The authors thank Dr. Richard Bannick and Ms. Amii Kress, Center for Health Care Management Studies, for their assistance with the interpretation of the study dataset and Lt. Col. Thomas A. Bacon, DoD Pharmacy Program/ OASD(HA)/TMA, for his review and input regarding this manuscript.

\section{DISCLOSURES}

This research was funded solely by the Department of Defense. Authors Andrea Linton, Mathew Garber, Nancy K. Fagan, and Michael Peterson are employed by the Department of Defense and hold no affiliation with organizations that may incur a financial benefit as a result of this work being published.

Author Andrea Linton served as principal author of this study. Study concept and design were contributed by Linton, Nancy Fagan, and Micheal Peterson. Data collection was the work of Linton, Fagan, and Peterson; data interpretation was primarily the work of Linton, with input from Mathew Garber Writing of the manuscript and its revision was primarily the work of Linton, with input from Garber, Fagan, and Peterson.

\section{REFERENCES}

1. Teagarden JR, Nagle B, Aubert RE, Wasdyke C, Courtney P, Epstein RS Dispensing error rate in a highly automated mail-service pharmacy practice. Pharmacotherapy. 2005;25(11):1629-35.

2. Xu KT. Choice of and overall satisfaction with pharmacies among a community-dwelling elderly population. Med Care. 2002;40(12):1283-93.

3. Johnson JA, Coons SJ, Hays RD, Sabers D, Jones R, Langley PC. A comparison of satisfaction with mail versus traditional pharmacy services. J Manag Care Pharm. 1997;3(3):327-37. Available at: http://www.amcp.org/data/jmcp/ research_v3_327-337.pdf.

4. Motheral BR, Heinle SM. Predictors of satisfaction of health plan members with prescription drug benefits. Am J Health Syst Pharm. 2004;61(10):1007-14. 


\section{Factors Associated With Choice of Pharmacy Setting Among DoD Health Care Beneficiaries Aged 65 Years or Older}

5. Birtcher KK, Shepherd MD. Users' perceptions of mail-service pharmacy. Am Pharm. 1992:NS32(12):35-41.

6. Office of the Assistant Secretary of Defense (Health Affairs) and the TRICARE Management Activity. TRICARE prescriptions homepage. Available at: http://www.tricare.osd.mil/pharmacy/default.cfm. Accessed April 27, 2005.

7. Stergachis A, Maine LL, Brown L. The 2001 National Pharmacy Consumer Survey. J Am Pharm Assoc (Wash). 2002;42(4):568-76

8. Lipowski EE. How consumers choose a pharmacy. Am Pharm. 1993;NS33 (suppl 12):S14-S17.

9. Cox ER, Henderson RR. Prescription use behavior among Medicare beneficiaries with capped prescription benefits. J Manag Care Pharm. 2002;8(5):360-64. Available at: http://www.amcp.org/data/jmcp/Research-360-364.pdf.

10. Spence MM, Hui R, Chan J. Cost reduction strategies used by elderly patients with chronic obstructive pulmonary disease to cope with a genericonly pharmacy benefit. J Manag Care Pharm. 2006;12(5):377-82. Available at: http://www.amcp.org/data/jmcp/research_377-382.pdf.

11. Motheral B, Cox ER, Mager D, Henderson R, Martinez R. Express Scripts prescription drug atlas. Available at: http://www.express-scripts.com/ ourcompany/news/outcomesresearch/prescriptiondrugatlas/entireStudy.pdf. Accessed July 2, 2007.

12. Schommer JC, Mott DA, Hansen RA, Cline RR. Selected characteristics of senior citizens' prescription drug payment and procurement in 1998 and 2001.
J Manag Care Pharm. 2003;9(5):408-15. Available at: http://www.amcp.org/ data/jmcp/Research-408-415.pdf.

13. Huskamp HA, Deverka PA, Epstein AM, Epstein RS, McGuigan KA, Frank RG. The effect of incentive-based formularies on prescription drug utilization and spending. N Engl J Med. 2003;349(23):2224-32.

14. Rector TS, Finch MD, Danzon PM, Pauly MV, Manda BS. Effect of tiered prescription copayments on the use of preferred brand medications. Med Care. 2003;41(3):398-406.

15. Thomas CP, Wallack SS, Lee S, Ritter GA. Impact of health plan design and management on retirees' prescription drug use and spending, 2001. Health Aff. December 4, 2002. Available at: http://content.healthaffairs.org/cgi/reprint/ hlthaff.w2.408v1. Accessed August 6, 2007.

16. O'Malley AJ, Frank RG, Kaddis A, Rothenberg BM, McNeil BJ. Impact of alternative interventions on changes in generic dispensing rates. Health Serv Res. 2006;41(5):1876-94

17. Henry J. Kaiser Family Foundation. Prescription drug trends, June 2006. Available at: http://www.kff.org/rxdrugs/upload/3057-05.pdf. Accessed July 3, 2007.

18. Linton A, Garber M, Fagan NK, Peterson MR. Examination of multiple medication use among TRICARE beneficiaries aged 65 years and older. J Manag Care Pharm. 2007;13(2):155-62. Available at: http://www.amcp.org/ data/jmcp/p155-62.pdf. 